\title{
O CONCEITO DE MODELO E SUA UTILIZAÇÃO NAS CIÊNCIAS DO COMPORTAMENTO: BREVES NOTAS INTRODUTÓRIAS.
}

\section{THE CONCEPT OF MODEL AND YOUR UTILIZATION IN THE BEHAVIORAL SCIENCES: INTRODUCTORY SHORT NOTES}

Amauri GOUVEIA JR

\begin{abstract}
RESUMO
O objetivo deste artigo é mapear as relações do conceito de modelo e sua utilização na pesquisa cotidiana em psicopatologia experimental. Para isto, aproximamos o conceito de modelo com o de metáfora e seus elementos.
\end{abstract}

Palavras chaves:modelos animais; modelos em psicologia; psicopatologia

\begin{abstract}
The subject of this paper is to mapping Ihe relationships of the concept of model and its utilization of this to the current research in experimental psychopathology. For this, we make an approximation to the concept of metaphor and its elements.
\end{abstract}

Keywords: Animal models; Models in Psychology; Psychopathology

\section{O CONCEITO DE MODELO}

O termo modelo vem do italiano módello, por sua vez, derivado do latim vulgar modellus, alteração feita ao latim modulus, o qual é diminutivo de modus, ou seja, medida. (Japiassu e Marcondes, 1989). Modelo é a forma ideal, o paradigma, tendo por função a criação de outros como ele. Já modelos teóricos são construções hipotéticas, teorizadas, modos de explicação que servem para a análise ou esclareci- mento de uma realidade concreta. (Japiassue Marcondes, 1989).

Para entender as características do conceito de modelo em seus termos essenciais é útil refletirmos sobre uma figura lingüística usada com grande freqüência: a metáfora.

Ao dizer: "fulano é burro como uma porta" ou, ainda, para a minha amada, "Teus olhos são duas pedras preciosas que brilham em meio ao seu rosto", estamos nos valendo de metáforas. Assim, tomamos um objeto qual- 
quer (fulano, os olhos da amada), e o relacionamos a outro (a porta, pedras preciosas), definindo pelo segundo as qualidades que são consideradas como existentes no primeiro (a capacidade de aprendizagem, o brilho), alterando o sentido das palavras, fazendo o que é chamado comumente de analogia.

De forma analógica, o modelo é um mecanismo qualquer alterado para ser a explicação do outro, assim, temos "pirâmides de trabalho" ou a "máquina humana". Mas, além disto, a metáfora e modelos são também coisas que se modificam segundo o lugar, momento histórico e posição social que são usadas. Um exemplo corriqueiro disto é como o nosso sistema nervoso central tem sido descrito ao longo das ultimas décadas: central telefônica, computador e, mais recentemente como holograma (Bond,1984), refletindo em suas metáforas os avanços da tecnologia de cada época.

A partir do que foi exposto até agora podemos determinar três elementos que seriam determinantes do que é metáfora e também do modelo: são eles a redutividade, a pontualidade e o que chamamos de Zeitgeist.

Comecemos pelo o ultimo, Zeitgeist é uma palavra de origem alemã que significa espírito de época e é usada para designar o conjunto de crenças e elementos que determinam a visão de mundo de determinado indivíduo ou classe dentro de um contexto social e histórico específico. Assim, quando um determinado cientista ou artista produz uma obra, sua produção não é uma coisa que surge de dentro dele ou do acaso, mas é o reflexo de sua posição social e crenças que permeiam o momento histórico onde vive. Desta forma, um erudito do inicio do século XIX não se referiria ao cérebro como computador por não conhecer tal instrumento, e, provavelmente rejeitaria a idéia de que os processamentos de informação nada mais são do que simples trocas químicas entre diversas regiões do cérebro, já que suas crenças essencialistas iriam contra isto. Isto é bem explicitado em Kuhn (1994)e Heisemberg (1958).
A redutividade pode ser definida como sendo o fato de que ao fazer um modelo (ou uma metáfora) eu escolho um número finito de elementos do objeto a serem representados por outro, assim, falo da burrice do fulano que é tal qual uma porta, mas não falo de sua feiura ou que a porta poderia ser também um ótimo modelo de resistência a mudanças.

A pontualidade pode ser entendida como sendo o fato de que modelos estão interessados em representar um dado fenômeno e não outro, assim, a burrice é de fulano e não de seu irmão, o brilho do olhar é de minha amada e não de minha sogra e o funcionamento do cérebro é semelhante ao de um computador, e não o de um fígado.

A pontualidade também pode ser o elemento distintivo entre modelos e teorias, pois, enquanto o primeiro se preocupa com fatos isolados, o segundo tenta criar sistemas explanatórios gerais que arrolam hipóteses que podem ser justificadas por modelos.

A psicologia, como todas as ciências apresenta sistemas teóricos que geraram modelos pontuais, reduzidos e sob influencia do Zeitgeist da época.

\section{Valoração dos modelos}

Um modeloé bom ou mau se sua utilidade dentro do espaço teórico onde foi criado é passível de mapeamento. Quanto maior o seu uso prático (valor de uso), possibilidade de previsão (valor preditivo) e similaridade com o fenômeno proposto (valor de face) melhor ele será considerado. Em resumo, podemos dizer que um modelo é bom quando funciona para os fins propostos. Desta forma, se os engenheiros químicos usam até hoje o modelo planetário de átomo quando existem modelos mais modernos é pelo fato de que este mostra-se funcional dentro das sua exigências.

Ouso de modelos animais é amplamente usado em outras ciências biológicas para estudos fisiológicos e farmacológicos, entre outros. Em psicologia seu uso remonta aos primórdios 
da psicologia científica, com o modelo de neurose de Pavlov.

\section{Modelos em psicopatologia}

O conceito de Psicopatologia é recente, sendo que somente após o século XVIé que a igreja deixou a guarda dos alienados para a nascente psiquiatria, e somente aí é que o desvio comportamental deixou de seu caracter místico-religioso para se constituir uma doença comotal (para uma revisão, ver Foucault,1972). Ainda assim há controvérsias quanto à classificação das doenças mentais como tal. Graeff (1983) lista alguns critérios para que uma doença possa ser classificada desta maneira, como patologia ou doença (Disease):

a - uma síndrome: conjunto característicos de sinais que andam juntos, podendo ser distintos de outras síndromes pela investigação clínica;

b - o decurso temporal da condição mórbida é previsível, permitindo prognósti$\cos \mathrm{e}$

c - identificam-se lesões orgânicas características nos exames histopatológicos e anatômicos, além das causas possíveis e suas manifestações, ou seja a etiologia e a fisiopatogenia, respectivamente, que permitam o desenvolvimento de tratamentos eficazes dos sintomas e causas da doença.

Graeff cita ainda que em psiquiatria algumas doenças atendem a todos estes critérios, como a pelagra ou a neurosífilis, mas que outras não, considera então um critério mais flexível, traduzível pela palavra perturbação ou distúrbio (IIness), que indica a presença de um sofrimento sem necessidade de correlato biológico direto. Para nós, no entanto, é importante que haja o desenvolvimento de um conceito de patologia animal, isto é, que possamos falar de alterações em animais, de forma a descrever funcionalmente e aproximadamente o que é pretendido, seja isto uma doença orgânica ou não. Assim, podemos dizer que em psicopatologia animal, tentamos descrever alterações da topografia ou funcionalidade do comportamento regular, que em sua similaridade possam ser tomadas como modelos.

\section{Validação dos modelos em psicopatologia experimental}

Mckinney (1977) cita 4 perguntas que devem ser respondidas para que um modelo animal possa ser considerado excelente:

1 - Este modelo descreve as causas e tratamentos essenciais da desordem a que se propõe modelar?

2 - Existe similaridadede sintomas entre a patologia e o modelo proposto?

3 - Existe um substrato biológico similar entre a patologia e o modelo?

4 - É um modelo específico para uma desordem particular ou simplesmente uma modelagem de aspectos gerais da psicopatologia humana?

Embora estas perguntas possam constituir-se em um parâmetro seguro para escolher e testar a validade de um modelo, elas apresentam algumas dificuldades (Bond, 1984). Assim, como ficam o desenvolvimento de modelos para patologias em que as causas e/ou tratamento não estão muito claras, assim como a síndrome de Rert e o autismo? Ou como poderemos testar certos sintomas que somente são passíveis de investigação pela linguagem ou que carecem de uma operacionalização mais clara, como a "tendência suicida" ou a "obsessão"? Como ficariam ainda as patologias que não têm base fisiológica ou funcional conhecida? E, por fim, a ultima pergunta: é mais útil desenvolver modelo de patologia ou modelo de sintomas? Não nos alongaremos nesta questão por ser ela uma área delicada e apaixonante, mas onde as discussões têm se mostrado infrutíferas (para uma discussão mais aprofundada ver Willner, 1991)

Uma solução possívelédesenvolver modelos humanos de sintomas psicopatológico, par- 
tindo do pressuposto que a ocorrência destes não é mais que a exacerbação de elementos encontrados no comportamento cotidiano dos sujeitos.

Outro caminho pressupõe que o comportamento animal e humano não são coisas diversas, mas fazem parte de um contínuo dentro da evolução (Skinner, 1984,1974) sendo selecionado pelas as suas conseqüências tanto na ontogênese, como na filogênese (Skinner, 1984,1974). Ao longo da evolução as espécies estão submetidas a pressões evolutivas diversas, gerando assim, mecanismos homólogos, isto é, diferentes entre si, mas com a mesma função. Já quando espécies são submetidas a pressões evolucionárias iguais, mas apresentam soluções evolutivas diversas, temos analogias. No entanto, muito pouco pode ser extrapolado diretamente no tocante a comportamento de uma espécie para a outra.

Boa parte das pesquisas desenvolvidas na área médica valem-sedo estudo de modelos analógicos que permitem extrapolações pontuais, naqueles aspectos que se mostram similares. Desordens orgânicas encontradas em seres humanos, tal qual o câncer, são desenvolvidas em outros animais e seus resultados são, em grande parte generalizados para a nossa espécie. No terreno da psicologia, o pensamento evolutivo ainda causa escândalo e é recebido com resistência por largos setores, já que há uma crença arraigada que o que chamamos de psiquismo é algo unicamente encontrado em seres humanos. É verdade que a analogia pura e simples não é de todo possível na Psicopatologia, mas também não é em outras ciências da saúde. Ainda assim, somos muito freqüentemente confrontados com analogias poderosas. Assim, em 1979 Cade (apud Bond, obra citada), injetou em cobaias urato de lítio, um sal bastante solúvel, a fim de testar a sua hipótese de que a mania era causada por um excesso de uréia no organismo. Em vez dos animais ficarem excitados, eles apresentaram letargia. Em um estudo posterior, com carbonato de lítio (um sal similar, mas que isolava os efeitos possíveis da uréia), Cade tratou 10 pacientes com mania com lítio e viu normalizar-se os seus humores, causando-Ihes redução da atividade motora de forma similar ao ocorrido nas cobaias.

Nestes experimentos, podemos ver que 0 autor valeu-se de elementos anteriormente discutidos. Estes e outros dados da literatura reforçam-nos a convicção da riqueza das possibilidades de pesquisa nesta área.

\section{REFERÊNCIAS BIBLIOGRAFIAS}

BOND, N.W.(1984) - Animal models in psychopathology: an introdution, em Bond, N.W. (org)(1984) - Animal models in psychophatology, Academic Press, inc. Australia

FOUCAUL T, M (1972) A história da loucura na idade classica, Perspectiva, S.Paulo

GRAEFF, F.G. e Brandão, M.L. (edit) (1993) Neurobiologia das doenças mentais, Lemos, S. Paulo.

HEISENBERG, W.(1958) Physicist's conception of nature, Londres: Hutchinson

JAPAISSU, He Marcondes, (1989) Pequeno dicionario de filosofia. São Paulo: Jorge Zahar Ed.

KUHL, T.S. (1994) A estrutura das revoluções científicas, (Série Debates, 115). São Paulo: Perspectiva

MCKINNEY, W. J. T. Behavioral models of depression in monkeys em I. Hanin e E. Usddin (eds). Animal Models in Psychiatry and Neurology. Oxford: Pergamon, 1977:17-26

SKINNER, B.F.(1974) About Behaviorism, New York: Knopf

SKINNER, B.F.(1984) Seletion by consequences, Behavioral and Brain Science,7(4):477-481

WILNNER, P (1991) (ed) Behavioral Models in Psychopharmachology: Theoretical, industrial and clinical perspectives, Cambridge University press, Cambridge 